\title{
DIGLOSIA
}

Volume 3, Nomor 1, Februari 2020, Halaman 79-86

p-ISSN 2615-725X (Print) e-ISSN 2615-8655 (Online)

http://diglosiaunmul.com/index.php/diglosia/article/view/37

\section{SOSIOPRAGMATIK IMPERATIF IKLAN PADA MEDIA SOSIAL}

\section{The Imperative Sociopragmatics of Advertising on Social Media}

\author{
Indah Rahmayanti ${ }^{1, *}$ \& Alvi Fajar ${ }^{2}$ \\ ${ }^{1,2}$ Universitas Muhammadiyah Prof. DR. HAMKA \\ Jakarta, Indonesia \\ *Pos-el Korespondensi: indah.rahmayanti@uhamka.ac.id
}

\begin{abstract}
This study aims to determine the imperative sociopragmatics form on social media ads Instagram, Facebook and Line published in April-May 2018. The method used in this study is descriptive qualitative method. The results of the analysis of this study reveal that there are 41 imperative sociopragmatic forms of 30 advertisements used as imperative sociopragmatics analysis material on social media Instagram, Facebook and LINE. The imperative sociopragmatics forms which have been analyzed are 19 advertisements in the form of imperative sociopragmatic, 2 advertisements in the form of imperative sociopragmatic demand, there are no ads in the form of imperative sociopragmatic licensing, 9 advertisements in the form of imperative sociopragmatic invitations, 11 advertisements in the form of imperative sociopragmatic orders. Based on the results of this analysis, it can be concluded that the form of sociopragmatics that often arises is ordinary sociopragmatics.
\end{abstract}

Keywords: imperative sociopragmatics, advertising, social media

\begin{abstract}
Abstrak: Penelitian ini bertujuan mengetahui bentuk sosiopragmatik imperatif pada iklan media sosial Instagram, Facebook, dan Line yang terbit pada bulan April-Mei 2018. Metode yang digunakan dalam penelitian ini adalah metode kualitatif deskriptif. Hasil analisis penelitian ini mengungkapkan, bahwa terdapat 41 bentuk sosiopragmatik imperatif dari 30 iklan yang dijadikan bahan analisis sosiopragmatik imperatif pada media sosial Instagram, Facebook, dan Line. Bentuk sosiopragmatik imperatif yang telah dianalisis adalah 19 iklan dalam bentuk sosiopragmatik imperatif biasa, 2 iklan dalam bentuk sosiopragmatik imperatif permintaan, tidak ada iklan dalam bentuk sosiopragmatik imperatif pemberian izin, 9 iklan dalam bentuk sosiopragmatik imperatif ajakan, 11 iklan dalam bentuk sosiopragmatik imperatif suruhan. Berdasarkan hasil analisis tersebut, dapat disimpulkan bahwa bentuk sosiopragmatik yang sering muncul adalah sosiopragmatik biasa.
\end{abstract}

Kata Kunci: sosiopragmatik imperatif, iklan, media sosial

\section{A. PENDAHULUAN}

Promosi salah satu cara untuk memperkenalkan suatu produk, melalui promosi produk akan lebih mudah dikenal masyarakat. Promosi sering dijumpai di kehidupan sosial kita, karena objek sasarannya adalah masyarakat luas. Misalnya sering kita jumpai di supermarket atau di sepanjang jalan terdapat reklame atau spanduk yang memaparkan diskon dalam peluncuran suatu produk. Itu semua merupakan bagian dari promosi untuk menarik calon konsumen untuk membelinya. Salah satu cara mempermudah melakukan suatu kegiatan promosi dengan menggunakan media promosi. Salah satu media promosi adalah periklanan (advertising). Perkembangan media informatika semakin membuat iklan menjadi lebih bervariasi. Media periklanan yang paling sering digunakan adalah televisi, koran, majalah, radio, spanduk, reklame serta internet. Hal ini dilakukan agar pesan yang disampaikan melalui iklan dapat sampai kepada masyarakat dengan lebih 
efektif. Dampak media dalam masyarakat membuat pandangan baru bahwa media massa dan masyarakat secara bersamaan saling berhubungan satu sama lain.

Sosiopragmatik salah satu cara untuk menelaah mengenai kondisikondisi dalam penggunaan bahasa. Sosiopragmatik salah satu bagian dari kajian pragmatik karena sosiopragmatik mengkaji makna yang terdapat dalam lingkungan-lingkungan sosial masyarakat salah satunya terdapat dalam suatu iklan. Menurut Hermawan (2017), iklan adalah suatu bentuk penyajian dari promosi nonpersonal atas ide, barang atau jasa yang dilakukan oleh perusahaan tertentu. Bentuk iklan dapat berupa tulisan, gambar, film, ataupun gabungan dari keseluruhan unsur. Sebagai salah satu alat promosi, iklan banyak dimuat di berbagai media. Penggunaan bahasa iklan menjadi salah satu aspek penting bagi keberhasilan iklan. Penggunaan bahasa dalam iklan disesuaikan dengan kebutuhan dan demi tercapainya maksud iklan itu sendiri. Oleh karena itu, bahasa iklan harus mampu menjadi manifestasi atau presentasi dari hal yang diinginkan pihak pengiklanan kepada masyarakat luas. Bahasa yang digunakan dalam iklan biasanya mengandung kalimat perintah (imperatif). Tujuannya untuk mempengaruhi masyarakat atau konsumen agar tertarik pada produk dan jasa yang ditawarkan oleh perusahaan. Terkadang bahasa yang dimuat dalam suatu iklan produk tidak bernalar atau tidak menggunakan bahasa Indonesia yang benar serta memiliki makna yang dapat membingungkan.

$$
\text { Menurut Tarigan (2015), }
$$

sosiopragmatik adalah telaah mengenai kondisi-kondisi setempat atau kondisikondisi lokal yang lebih khusus mengenai penggunaan bahasa. Sedangkan menurut Leech (2011), sosiopragmatik didasarkan pada kenyataan bahwa prinsip kerja sama dan prinsip sopan santun beroperasi secara berbeda dalam kebudayaankebudayaan dan masyarakat bahasa yang berbeda, dalam situasi-situasi yang berbeda, dalam kelas-kelas sosial yang berbeda, dan sebagainya. Sedangkan menurut Rahardi (2009) kajian sosiopragmatik itu secara konkret merupakan kajian terhadap entitas kebahasaan yang menggabungkan ancangan penulisan sosiolinguistik dan ancangan pragmatik dalam wadah dan dalam lingkup kebudayaan atau jangkauan kultur tertentu." Jadi dapat disimpulkan bahwa sosiopragmatik adalah suatu kajian kebahasaan yang melihat makna pada penggunaan bahasa yang terdapat dalam lingkungan sosial. Sosiopragmatik salah satu cara untuk menelaah mengenai kondisi-kondisi dalam penggunaan bahasa. Sosiopragmatik salah satu bagian dari kajian pragmatik karena sosiopragmatik mengkaji makna yang terdapat dalam lingkungan-lingkungan sosial masyarakat salah satunya terdapat dalam suatu iklan.

Sosiopragmatik dalam iklan merupakan kalimat imperatif. Kalimat imperatif mengandung maksud memerintah atau meminta agar mitra tutur melakukan sesuatu sesuai apa yang diinginkan penutur. Kalimat imperatif merupakan kalimat yang dipakai jika penutur ingin menyuruh atau melarang orang melakukan sesuatu. Menurut Edy (2013), kalimat perintah biasanya berisi kata-kata tindak tutur yang secara eksplisit menyatakan meminta, atau menyuruh. Kalimat imperatif atau kalimat perintah adalah kalimat yang mengharapkan tanggapan yang berupa tindakan dari seseorang yang diajak berbicara (Purba et al., 2002). Kalimat imperatif bahasa Indonesia dapat diklasifikasikan secara formal menjadi lima macam, yakni (1) kalimat imperatif biasa, (2) kalimat imperatif permintaan, (3) kalimat imperatif pemberian izin, (4) kalimat imperatif ajakan, dan (5) kalimat imperatif suruhan (Rahardi, 2005). Imperatif memiliki sifat memberi komando, bersifat memerintah; mempunyai hak memberi 
komando; bersifat menguatkan; bentuk perintah untuk kalimat yang menyatakan larangan atau keharusan melaksanakan sesuatu (Tim Reality, 2008). Oleh karena itu, kajian sosiopragmatik imperatif sangat tepat digunakan untuk memahami iklan karena kajian sosiopragmatik imperatif mempunyai kemampuan untuk mempermudah mengkaji makna yang terdapat dalam iklan agar lebih mudah dipahami. Dengan adanya kajian sosiopragmatik, masyarakat tidak lagi mengalami kesulitan dalam memahami pesan yang terdapat dalam iklan sesuai dengan kondisi lingkungan sosial.

Ketertarikan dalam menganalisis bahasa iklan dipengaruhi karena bahasabahasa yang digunakan dalam iklan cukup beragam dan kata-kata yang digunakan sering menggunakan kata-kata yang tren dan gaul sehingga dapat menciptakan ketertarikan yang lebih kepada masyarakat yang membacanya. Tujuan dari pembahasan ini agar bermanfaat memberikan informasi dalam bentuk memaknai imperatif bahasa iklan serta makna sosiopragmatik bahasa iklan, memberikan pengetahuan terhadap perkembangan pembelajaran Bahasa Indonesia khususnya dibidang kebahasaan. Pembahasan tentang iklan dalam penelitian ini terdapat dalam kurikulum SMA 2013 pada kelas XII SMA yang terdapat pada kompetensi dasar 3.1, yaitu memahami struktur dan kaidah teks iklan, baik melalui lisan maupun tulisan dan pada kompetensi dasar 4.1, yaitu menginterpretasi makna teks iklan, baik secara lisan maupun tulisan. Sosiopragmatik imperatif diajarkan kepada siswa untuk mengetahui segala sesuatu tentang imperatif dalam kalimat itu sendiri, baik itu makna atau pun jenis-jenisnya.

Sosiopragmatik imperatif juga diajarkan bertujuan untuk membantu siswa dalam memaknai suatu bahasa yang terkandung, khususnya pada iklan yang biasa dilihat sehari-hari. Relevansi penelitian dari Jurnal yang dibuat oleh Riza Umami, Diana Kartika, dan Anwar Nasihin, mahasiswa jurusan Sastra Asia Timur, Fakultas Ilmu Budaya, Universitas Bung Hatta yang berjudul "Makna Imperatif yang terkandung pada Iklan Kosmetik Berbahasa Jepang dalam majalah Popteen". Berdasarkan hasil analisis yang telah dilakukan, maka dapat diketahui bahwa terdapat makna imperatif yang paling banyak ditemukan dalam majalah Popteen adalah iklan membujuk yang menyatakan imperatif bujukan data yang ditemukan 8 data. Makna imperatif yang paling sedikit ditemukan dalam majalah Popteen iklan membujuk yang menyatakan imperatif imbauan dan iklan mengingatkan yang menyatakan imperatif suruhan sebanyak masing-masing 1 data.

\section{B. METODE}

Penelitian ini dilakukan mulai bulan Maret 2018 sampai bulan Oktober 2018. Penelitian ini merupakan penelitian studi kepustakaan. Media sosial digunakan sebagai bahan penelitian. Penelitian ini dilakukan untuk mengetahui sosiopragmatik imperatif yang terdapat dalam iklan pada media sosial serta implikasinya terhadap pembelajaran bahasa Indonesia di SMA. Media untuk iklan banyak jenisnya, tetapi peneliti membatasi iklan yang dianalisis hanya yang terdapat di media sosial yaitu Instagram, Facebook, dan Line. Hal ini berhubungan dengan kajian sosiopragmatik yang mengkaji makna yang terdapat di lingkungan sosial.

Metode yang digunakan dalam penelitian kualitatif ini adalah metode deskriptif yaitu menganalisis dengan mendeskripsikan iklan sesuai dengan kajian sosiopragmatik imperatif. Menurut Hikmawati (2017) penelitian deskriptif merupakan penelitian bukan eksperimen karena tidak dimaksudkan untuk menguji hipotesis tertentu, tetapi hanya menggambarkan "apa adanya" tentang 
gejala, atau keadaan. Penelitian ini menggunakan metode deskriptif untuk menggambarkan atau mendeskripsikan sosiopragmatik imperatif berdasarkan jenis-jenisnya antara lain imperatif biasa, imperatif permintaan, imperatif pemberian izin, imperatif ajakan dan imperatif suruhan pada iklan dalam media sosial (Instagram, Facebook dan Line).

Data dari analisis menggunakan teknik analisis dengan langkah-langkah sebagai berikut: (1) mengumpulkan iklan dari berbagai media sosial, yaitu Instagram, Facebook, dan Line, (2) melakukan pemilihan analisis kata-kata, frasa, klausa, atau kalimat sebagai data yang akan digunakan untuk penelitian, yaitu ungkapan-ungkapan yang mengandung sosiopragmatik imperatif, mendeskripsikan data dari sumber data berdasarkan jenis-jenis imperatif (imperatif biasa, imperatif permintaan, imperatif pemberian izin, imperatif ajakan, imperatif suruhan), (4) merumuskan kesimpulan atas penelitian yang telah dilakukan. Selain itu, sebagai penunjang informasi juga digunakan beberapa referensi untuk sumber data, yaitu buku-buku yang berhubungan dengan teori sosiopragmatik imperatif. Triangulasi pemeriksaan data mencakup triangulasi sumber dilakukan dengan membandingkan dan meninjau kembali data hasil pemerhatian dengan hasil wawancara dan triangulasi dengan metode membandingkan data meninjau informasi wawancara serta teori-teori terkait.

\section{PEMBAHASAN}

Data didapatkan dari media sosial berupa iklan produk dan jasa yang mengandung imperatif pada bahasa iklan. Temuan yang didapatkan peneliti menguraikan hasil analisis iklan-iklan yang terdapat dalam media sosial (Instagram, LINE, Facebook) bulan April-Mei. Hasil analisis berikut ini berupa iklan-iklan yang mengandung sosiopragmatik imperatif biasa, sosiopragmatik imperatif permintaan, sosiopragmatik imperatif pemberian izin, sosiopragmatik imperatif ajakan dan sosiopragmatik imperatif suruhan. Adapun hasil analisis bahasa Iklan dalam media sosial (Instagram, Facebook, dan Line) sebagai berikut.

\section{Sosiopragmatik Imperatif Biasa}

a. Downy Indonesia (Instagram, 9 April 2018/23:27 WIB)

\author{
Indonesia: negara tropis \\ Dengan suhu mencapai $35^{\circ} \mathrm{C}$. \\ Makin panas, \\ Wangi bajumu \\ Makin cepat hilang :( \\ Tinggal di Indonesia pasti akrab sama cuaca \\ panas. Swipe dan temukan rahasia baju wangi \\ terus di tengah cuaca panas! \\ Dapatkan di Indomaret.
}

Downy Indonesia merupakan nama perusahaan pewangi pakaian di Indonesia. Iklan ini memiliki makna sosiopragmatik imperatif biasa terdapat pada kalimat Dapatkan di Indomaret kalimat ini memiliki makna perintah biasa yang bertujuan untuk memberikan perintah kepada masyarakat yang ingin membeli produk Downy dapat didapatkan di Indomaret.
b. Shopee: No.1 Tempat Belanja Online se-Indonesia (Instagram, 12 April 2018/23:13 WIB)

\footnotetext{
Temukan semua barang yang kamu mau dengan harga terbaik hanya di Shopee: No.1 Tempat Belanja Online se-Indonesia! Tinggal Download, dan nikmati beragam pilihan dari Star Sellers yang berkualitas!
}

Shopee merupakan salah satu jasa jual beli online di Indonesia. Iklan ini memiliki makna sosiopragmatik imperatif biasa. Sosiopragmatik imperatif biasa pada iklan ini terdapat pada kalimat Temukan semua barang yang kamu mau dengan harga terbaik hanya di Shopee: No.1 Tempat Belanja Online se-Indonesia! Kalimat ini memiliki makna perintah kepada 
masyarakat atau pembaca iklan khususnya yang memiliki aplikasi Shopee untuk menemukan barang-barang yang ingin dicari dengan harga yang terbaik hanya di Shopee.

\section{c. Alfamart (Instagram, 13 April 2018/10:58 WIB)}

Weekend telah tiba! Dapatkan berbagai promo JSM Alfamart yang serba murah dan serba gratis! Promonya Cuma 3 hari saja loh, 13-15 April 2018. Ayo segera dapatkan promonya di Alfamart sebelum kehabisan!

Alfamart merupakan jaringan minimarket yang menjual berbagai barang kebutuhan hidup. Iklan ini menginfokan kepada masyarakat bahwa Alfamart sedang mengadakan promo JSM dengan menjual barang-barang yang lebih murah. Iklan ini memiliki makna sosiopragmatik imperatif biasa terdapat pada kalimat Dapatkan berbagai promo JSM Alfamart yang serba murah dan serba gratis! kalimat ini memiliki makna perintah kepada masyarakat agar mendapatkan atau membeli barang-barang yang diperlukan dengan berbagai promo yang telah disediakan oleh Alfamart.

d. Tokopedia-Jual Beli Online \& Pulsa (Facebook, 7 April 2018/09:29 WIB)

Weekend emang paling seru buat nge-game. Apalagi ada promo voucher game khusus weekend di sini, raih cashback s.d 150 rb. Beli sekarang!

Tokopedia adalah salah satu jasa jual beli online di Indonesia. Iklan ini memberikan informasi kepada masyarakat bahwa Tokopedia sedang mengadakan promo voucher game khusus hari libur. Promo tersebut berupa cashback s.d 150 ribu. Iklan ini memiliki makna sosiopragmatik imperatif biasa yang terdapat pada kalimat Beli sekarang! Kalimat tersebut memiliki makna perintah kepada masyarakat khususnya pecinta game untuk membeli voucher game di Tokopedia dan merasakan promo yang diberikan oleh pihak Tokopedia. Iklan tersebut bertujuan agar masyarakat menggunakan jasa jual beli Tokopedia.

$$
\text { e. Line Event (Line, } 12 \text { April }
$$

\section{LINE STICKERS}

SALSHABILLA

Kirim stikernya ke banyak teman dan menangkan sehari Bersama Salshabilla

Iklan yang diterbitkan oleh Line Event ini mempromosikan suatu fitur Line, yaitu berupa Sticker yang bermotif animasi wajah dari aktris dan penyanyi berkebangsaan Indonesia, Salshabilla. Iklan ini memiliki makna sosiopragmatik imperatif biasa yang terdapat pada kalimat Kirim stikernya ke banyak teman dan menangkan sehari Bersama Salshabilla. Kalimat ini bermakna perintah kepada masyarakat khususnya pengguna aplikasi Line untuk mengunduh sticker Salshabilla dan mengirimkan stiker tersebut ke teman-teman sesama pengguna aplikasi Line agar dapat memenangkan hadiah yang berupa bertemu dengan Salshabilla selama sehari.

\section{Sosiopragmatik Imperatif Permintaan \\ a. Tokopedia (Instagram, 10 April 2018/23:02 WIB)}

Top Up hingga Bayar Tagihan Jangan lewatkan! Top up, bayar tagihan, hingga cicilan ada cashback s.d. 100rb! Plus Kejutan 2x Cashback menunggu.

Tokopedia merupakan salah satu jasa jual beli online yang ada di Indonesia. Iklan yang dibuat Tokopedia melalui media sosial Instagram memiliki makna sosiopragmatik imperatif permintaan. Sosiopragmatik imperatif permintaan yang terdapat dalam iklan ini terdapat dalam kalimat Jangan lewatkan! Top up, bayar tagihan, bingga cicilan ada cashback s.d. 100rb! Kalimat ini memiliki makna 
perintah permintaan kepada pengguna Instagram atau masyarakat agar tidak sampai ketinggalan.

b. Line Event (Line, 28 Mei 2018/11:41 WIB)

\section{LINE SHOPPING X LINE STICKERS \\ PHR Point Hari Raya \\ Belanja Apapun Dapatkan 3.000 LINE POINTS}

Hi sahabat LINE! Ingin mendapatkan 3.000 LINE Point gratis dari LINE? Yuk, ikuti langkah-langkah berikut!

CARA BERPATISIPASI

1 Beli produk apapun di LINE Shopping (Tidak ada minimum pembelian

2 Pastikan pemesanan dilakukan pada periode promosi (29 Mei-3 Juni 2018), dan segera selesaikan transaksi (pembayaran) kamu untuk dapat mengikuti event ini.

PERIODE PROMOSI

29 Mei 2018 - 3 Juni 2018

Klik disini untuk info lebih lanjut!

Iklan ini menginformasikan bahwa Line Shopping dan Line Sticker sedangan bekerja sama dalam melaksanakan event PHR (Poin Hari Raya) yaitu event yang memberikan Line Point setiap berbelanja di Line Shopping dan Line Sticker. Iklan ini memiliki makna sosiopragmatik imperatif permintaan. Makna sosiopragmatik imperatif permintaan terdapat pada kalimat Pastikan pemesanan dilakukan pada periode promosi (29 Mei-3 Juni 2018), dan segera selesaikan transaksi (pembayaran) kamu untuk dapat mengikuti event ini. Kalimat ini bermakna permintaan untuk masyarakat atau pengguna LINE yang sedang mengikuti event tersebut dan sudah membeli salah satu produk, untuk segera memastikan pemesanan dilakukan pada periode yang sudah ditentukan dan segera menyelesaikan transaksi pembayaran agar dapat mengikuti event tersebut dengan benar.

\section{Sosiopragmatik Imperatif Pembe- rian Izin}

Iklan-iklan yang telah dijadikan sebagai bahan analisis dari media sosial
Instagram, Facebook, dan Line yang terbit pada bulan April-Mei 2018 tidak terdapat iklan yang mengandung makna sosiopragmatik imperatif pemberian izin.

\section{Sosiopragmatik Imperatif Ajakan}

a. Explore_serang: bank bjb dan pesona Indonesia (Instagram, 2 April 2018/16:34 WIB)

\author{
Salam dulur! \\ Pendaftaran Pemilihan Duta Wisata \\ Kabupaten Serang 2018 telah DIBUKA! \\ Ayo tunjukkan kemampuan dan kontribusimu \\ dalam memajukan budaya dan pariwisata \\ Kabupaten Serang dengan mengikuti ajang ini. \\ Segera daftarkan diri kamu di \\ @kangkongkabsrg@disporaparkabserang.
}

Explore_serang adalah salah satu akun sosial media yang memberikan berbagai macam informasi yang ada di kabupaten Serang dan sekitarnya. Iklan ini berisikan informasi yang diberikan oleh akun media sosial Explore_serang mengenai pendaftaran pemilihan duta wisata kabupaten Serang. Acara tersebut di dukung oleh Bank BJB dan Pesona Indonesia. Iklan ini memiliki makna sosiopragmatik imperatif ajakan. Sosiopragmatik imperatif ajakan terdapat dalam kalimat Ayo tunjukekan kemampuan dan kontribusimu dalam memajukan budaya dan pariwisata Kabupaten Serang dengan mengikuti ajang ini. Kalimat ini memiliki makna mengajak kepada seluruh pemuda/pemudi kabupaten Serang agar menunjukkan kemampuan dan berkontribusi dalam memajukan budaya dan pariwisata Kabupaten Serang.

b. Wongcoco.id (Instagram, 7 April 2018/08:15 WIB)

Yuk,ikuti kuis di@wongcoco.id sekarang. Ajak teman buat ikutan dan menangkan hadiahnya!

Wongcoco.id adalah salah satu akun media sosial Instagram. Wongcoco.id sedang mengadakan kuis. Kuis ini 
bertujuan untuk meningkatkan ketertarikan masyarakat untuk membeli produk dari Wongcoco. Iklan ini mengandung sosiopragmatik imperatif ajakan. Sosiopragmatik imperatif ajakan terdapat pada kalimat Yuk, ikuti kuis di @wongcoco.id sekarang. Kalimat ini memiliki makna perintah ajakan kepada konsumen dan pengguna media sosial Instagram untuk mengikuti kuis yang diadakan oleh Wongcoco.id.

\section{Sosiopragmatik Imperatif Su- ruhan \\ a. BosquId (Instagram, 7 April 2018/12:41 WIB)}

BUTUH PENGHASILAN ++ YA BOSQU

Kini semua orang bisa jadi BOS. Penasaran? Langsung saja coba bisnis voucher pulsa, game, PLN, hingga pembayaran BPJS dan internet dengan BOSQU sekarang juga!

BosquId merupakan salah satu jasa distributor penjualan pulsa, game, PLN, hingga pembayaran BPJS dan internet. Iklan ini memiliki makna sosiopragmatik imperatif suruhan yang terdapat pada kalimat Lansungsaja coba bisnis voucer pulsa, game, PLN, bingga pembayaran BPJS dan internet dengan BOSQU sekarang juga! Kalimat ini memiliki makna perintah suruhan kepada pengguna Instagram atau masyarakat yang ingin memiliki penghasilan atau pekerjaan untuk mencoba langsung bisnis yang ditawarkan oleh BosquId.

b. Google (Facebook, 1 Mei 2018/23:36 WIB)

Google Maps kini hadir dengan rute khusus motor. Coba sekarang agar perjalananmu \#BebasMelaju

Google adalah sebuah perusahaan khusus pada jasa dan produk internet. Salah satu layanan yang dikembangkan oleh Google, yaitu Google Maps. Iklan ini memberikan informasi kepada masyarakat.

Temuan yang didapatkan peneliti yaitu terdapat 30 iklan pada media sosial (10 iklan pada media sosial Instagram, 10 iklan pada media sosial Facebook dan 10 iklan pada media sosial Line). Berdasarkan hasil temuan yang telah peneliti analisis, terdapat 41 bentuk sosiopragmatik imperatif dalam 30 iklan di media sosial. Analisis sosiopragmatik imperatif yang terkandung dalam iklan pada media sosial (Instagram, Facebook dan Line) yang terbit sejak bulan April-Mei 2018 sebagai berikut.

\section{Tabel 1. Hasil Analisis}

\begin{tabular}{clc}
\hline No & \multicolumn{1}{c}{ Wujud Sosiopragmatik Imperatif } & Jumlah Iklan \\
\hline 1 & Sosiopragmatik Imperatif Biasa & 19 \\
2 & Sosiopragmatik Imperatif Permintaan & 2 \\
3 & Sosiopragmatik Pemberian Izin & 0 \\
4 & Sosiopragmatik Imperatif Ajakan & 9 \\
5 & Sosiopragmatik Imperatif Suruhan & 11 \\
\hline & Jumlah & $\mathbf{4 1}$ \\
\hline
\end{tabular}

Berdasarkan hasil perhitungan di atas, terdapat 41 bentuk sosiopragmatik imperatif dari 30 iklan yang dijadikan sebagai bahan analisis sosiopragmatik imperatif. Iklan yang mengandung makna sosiopragmatik imperatif pada media sosial (Instagram, Facebook dan Line) yang terbit pada bulan April-Mei 2018, maka dapat dinyatakan bahwa sosiopragmatik imperatif yang sering muncul adalah sosiopragmatik imperatif biasa yaitu sebanyak 19 iklan dari 30 iklan yang dijadikan sebagai bahan penelitian yang terdapat pada media sosial (Instagram, 
Facebook dan Line) yang terbit pada bulan April-Mei 2018.

\section{PENUTUP}

Hasil analisis penelitian ini mengungkapkan, bahwa terdapat 41 bentuk sosiopragmatik imperatif dari 30 iklan yang dijadikan bahan analisis sosiopragmatik imperatif pada media sosial Instagram, Facebook dan Line. Bentuk sosiopragmatik imperatif yang telah dianalisis adalah 19 iklan dalam bentuk sosiopragmatik imperatif biasa, 2 iklan dalam bentuk sosiopragmatik imperatif permintaan, tidak ada iklan dalam bentuk sosiopragmatik imperatif pemberian izin, 9 iklan dalam bentuk sosiopragmatik imperatif ajakan, 11 iklan dalam bentuk sosiopragmatik imperatif suruhan. Berdasarkan hasil perhitungan di atas, maka dapat disimpulkan bahwa sosiopragmatik yang sering muncul adalah sosiopragmatik imperatif biasa yaitu sebanyak 19 iklan dari 30 iklan yang dijadikan sebagai bahan penelitian yang terdapat pada media sosial (Instagram,
Facebook dan Line) yang terbit pada bulan April-Mei 2018.

\section{DAFTAR PUSTAKA}

Chaer, A. (2009). Sintaksis Bahasa Indonesia. Jakarta: PT. Rineka Cipta.

Hermawan, A. 2012. Komunikasi Pemasaran. Jakarta: Erlangga.

Hikmawati, F. (2017). Metodologi Penelitian. Depok: Rajawali Press.

Leech, G. (2011). Prinsip-prinsip pragmatik. Jakarta: Universitas Indonesia. UI Press.

Purba, T. T. \& Paidi, Y. (2002). Sintaksis Bahasa Gresi. Jakarta: Pusat Bahasa, Departemen Pendidikan Nasional.

Rahardi, K. (2005). Pragmatik Kesantunan Imperatif Bahasa Indonesia. Jakarta: Erlangga.

Rahardi, K. (2009). Sosiopragmatik. Jakarta: Erlangga.

Reality, Tim. (2008). KamusTerbaru Bahasa Indonesia. Surabaya: Reality Publisher.

Tarigan, H. G. (2015). Pengajaran Pragmatik. Bandung: Angkasa. 